\title{
PENGARUH PENERAPAN METODE CRM (COSTEMER RELATIONSHIP MANAGEMENT) TERHADAP PUS (PASANGAN \\ USIA SUBUR) DAN ASEPTOR KB KHUSUSNYA JENIS KB HORMONALUNTUK MENINGKATKAN KEPATUHAN BERKUNJUNG SESUAI JADWAL DI RUMAH SAKIT UMUM IMELDA PEKERJA INDONESIA (RSU IPI) MEDAN TAHUN 2019
}

\author{
${ }^{1}$ Sarida Surya Manurung, ${ }^{2}$ Mahmudah Rizky \\ Universitas Imelda Medan, Jl. Bilal No. 52 Kelurahan Pulo Brayan Darat I Kecamatan Medan Timur, \\ Medan - Sumatera Utara. \\ E-mail: ${ }^{1}$ sarida.manurung1@gmail.com \\ ${ }^{2}$ mahmudahrizky@gmail.com
}

\begin{abstract}
ABSTRAK
Program KB (Keluarga Berencana) di wilayah kerja RSU (IPI) Medan.Kesadaran mengenai pentingnya kontrasepsi di Indonesia masih perlu ditingkatkan dan diingatkan kembali kepada Aseptor KB untuk berkunjung sesuai jadwal guna mencegah terjadinya peningkatanjumlah penduduk di Indonesia dan menurunkan tingkat kegagalan dalam program Keluarga Berencana (KB). Customer Relationship Management (CRM) merupakan istilah industri teknologi informasi untuk kombinasi antara metodologi, strategi dan perangkat lunak (software) yang dibuat untuk membantu sebuah perusahaan dalam mengelola hubungannya dengan para pelanggan.CRM dapat digunakan sebagai jembatan pelayanan kesehatan kepada akseptor KB dalam hal penyampaian informasi terkait kontrasepsi, misalnya informasi kepada akseptor KB suntik untuk mendapatkan pelayanan KB sesuai jadwal di wilayah kerja RSU (IPI) Medan. Penelitian ini bertujuan untuk melihat dan mengetahuiPenerapan Metode CRM (Costemer Relationship Management) Terhadap PUS (Pasangan Usia Subur) dan Aseptor KB khususunya jenis KB Hormonal Untuk Meningkatkan Kepatuhan Berkunjung Sesuai Jadwal Di Rumah Sakit Umum Imelda Pekerja Indonesia (RSU IPI) Medan Tahun 2019. Penelitian ini menggunakan Quasy eksperimen design tanpa pembanding, degan populasi berjumlah 61 orang perbulan dan pengambilan sampel dengan metode non probability sampling menggunakan accidental sampling. Teknik analisa data dengan menggunakan analisa data univariate dan bivariate dengan taraf signifikan 95\% ( $\leq 0,05)$. Hasil penelitian ini menunjukkan bahwa adanya Pengaruh Penerapan Metode CRM (Costemer Relationship Management) Terhadap PUS (Pasangan Usia Subur) Khususnya Aseptor KB Untuk Meningkatkan Kepatuhan Berkunjung Sesuai Jadwal dengan nilai $P=0,000 \pm \leq 0,05$ di RSU (IPI) Medan tahun 2019. Berdasarkan hasil penelitian diharapkan kepada petugas kesehatan dan peneliti dapat memahami dan meningkatkan pemberian KIE pada ibu.
\end{abstract}

Kata kunci : Akseptor, Customer Relationship Management, CRM, KB, SMS.

\begin{abstract}
Family Planning Program in the working area of RSU (IPI) Medan. Awareness about the importance of contraception in Indonesia still needs to be improved and reminded to KB acceptors to visit on schedule to prevent the increase in population in Indonesia and reduce the failure rate in the Family Planning program $(K B)$. Customer Relationship Management (CRM) is an information technology industry term for a combination of methodology, strategy and software created to help a company manage its relationships with customers. CRM can be used as a bridge of health services to family planning acceptors in the delivery of information related to contraception, for example information to injecting family planning acceptors to get family planning services according to the schedule in the working area of Medan General Hospital (IPI). This study aims to see and find out the Implementation of the CRM (Costemer Relationship Management) Method for PUS (Fertile Age Pairs) and KB acceptors, specifically the Hormonal KB type to Increase Visiting Compliance according to Schedule at the Imelda Indonesia Workers General Hospital (RSU IPI) Medan in 2019. Research This uses a Quasy design experiment without comparison, with a population of 61 people per month and sampling using a non-probability sampling method using accidental sampling. Data analysis techniques using univariate and bivariate data analysis with a significant level of 95\% ( $\leq 0.05)$. The results of this study indicate that the influence of the adoption of the CRM (Costemer Relationship Management) Method on PUS (Fertile Age Pairs) Especially KB Acceptors To Increase Visit Compliance on Schedule with a value of $P=0,000 \pm \leq 0.05$ in Medan General Hospital (IPI) in 2019.
\end{abstract}


Based on the results of the study it is expected that health workers and researchers can understand and improve the provision of IEC to Mother

Keywords: Acceptor, Customer Relationship Management, CRM, KB, SMS

\section{PENDAHULUAN}

Berbagai negara dibelahan dunia telah berkomitmen secara serius dalam menggapai target MDGs (Millenium Development Goals), termasuk negara Indonesia dengan targetnya adalah tercapai kesejahteraan rakyat dan pembangunan masyarakat. Pembangunan keluarga sejahtera diarahkan secara terpadu untuk mewujudkan keluarga kecil, bahagia dan sejahtera khususnya melalui pembudayaan KB (Keluarga Berencana) dalam rangka pengendalian laju pertumbuhan penduduk yang menjangkau segenap lapisan dan golongan masyarakat dengan tetap menjunjung tinggi moral, etika dan sosial budaya masyarakat (BKKBN, 2010).

Keluarga Berencana (KB) adalah salah satu cara untuk mencapai kesejahteraan keluarga dalam memberikan nasehat perkawinan, pengobatan kemandulan dan penjarangan kehamilan, pembinaan ketahan keluarga, meningkatkan keperdulian dan peran serta masyarakat melalui pendewasaan usia perkawinan, serta untuk mewujudkan keluarga kecil yang bahagia dan sejahtera (Depkes RI, 2009).

Pertumbuhan penduduk di Indonesia cukup tinggi yaitu $1.38 \%$ pertahun. Faktor utama yang memengaruhi pertumbuhan penduduk adalah tingginya angka kelahiran. Keadaan ini merupakan salah satu masalah kependudukan Indonesia sehingga memerlukan kebijakan kependudukan. Kebijakan tersebut dilakukan dengan cara menurunkan tingkat pertumbuhan serendahrendahnya. Cara efektif untuk menurunkan angka pertumbuhan penduduk dengan jalan mengikuti Keluarga Berencana (Octavianna, 2009).

World Health Organization (WHO) jumlah pengguna kontrasepsi suntik yaitu sebanyak 4.000.000 orang. Di Amerika Serikat jumlah pengguna kontrasepsi suntik sebanyak 30\%. Berdasarkan Survei Demografi dan Kesehatan Indonesia (SDKI) tahun 2012 terdapat kecenderungan peningkatan jumlah pemakai kontrasepsi dimana Intra Uterina Device (IUD) 7,75\%, MOW 1,52\%, MOP 0,25\%, kondom 6,09\%, implan 9,23\%, suntikan 48,56\%, pil 26,60\%.
Metode kotrasepsi jenis injeksi merupakan kontrasepsi yang paling bsnyak digunakan di Indonesia (Depkes.co.id). Pada Agustus 2013 dari 5.547.543 peserta yang aktif $49,55 \%$ nya adalah peserta akseptor KB Suntik. Di Sumatera Barat tahun 2012 pencapaian jumlah akseptor KB aktif yang terdiri dari akseptor suntik $45,06 \%$, akseptor pil $21,08 \%$, akseptor implant 11,75\%, akseptor IUD 6,09\%, MOP/MOW 1,50\% (BKKBN, 2013). Di kabupaten Agam tahun 2012 pencapaian KB suntik yaitu sebanyak 23.839 orang $(56,0 \%)$, kontrasepsi pil sebanayk 7.044 orang $(16,5 \%)$, IUD 4.594 orang $(10,7 \%)$, kondom sebanyak (2.839 orang $(6,7 \%)$, implant 2.634 orang $(6,2 \%)$, MOW $1.692(0,3 \%)$ dan MOP 1 orang $(0,0 \%)$ (DKK Agam, 2012).

Angka laju pertumbuhan penduduk Kota Medan menurut data Badan Psusat Statistik 2015 sebesar 0,89 persen TFR 2,12 dengan jumlah penduduk sebesar 2.210.624 jiwa, dari data kependudukan tersebut diatas dinilai sudah cukup baik walaupun jumlah penduduk kota ini sudah melampaui angka 2 juta jiwa. Apabila pertumbuhan penduduk tidak terkendali dan tidak di tangani pada masa mendatang akan menjadi salah satu kendala dalam pembangunan di beberapa sektor (Dinkes Prop.sumatra utara, 2018).

Menurut Undang-Undang No 52 Tahun 2009 tentang Perkembangan Kependudukan dan Pembangunan Keluarga, menjelaskan tentang bagaimana mengatur atau mengendalikan tatanan kependudukan terkait dengan angka kelahiran, angka kematian, serta perpindahan penduduk agar menjadi suatu tatanan penduduk yang merata dan berbanding dengan perekonomian masyarakat. Permasalahan kependudukan di Indonesia khusus nya di Kota Medan perlu perhatian yang cukup serius dari semua pihak, baik pemerintah maupun non pemerintah. Jika tidak ditangani maka berakibat kota Medan akan terjadi ledakan penduduk, meningkatnya kemiskinan serta menurunnya kesehatan masyarakat, sehingga daya saing bangsa semakin rendah. Dari permasalahan penduduk tersebut maka perlu adanya suatu kebijakan program sebagai upaya dalam pengendalian kelahiran. Maka melalui berbagai kebijakan, 
strategi, program dan kegiatan upaya penurunan angka kelahiran maka dilaksanakan program keluargaberencana yang bertujuan menjadikan masyarakat untuk mencapai suatu kesejahteraan (World Health Organization, 2018)

Berdasarkan survei awal dari sistem Informasi Rumah Sakit (SIRS) Di Rumah Sakit Umum Imelda Pekerja Indonesia, Aseptor KB yang berkunjung ke BKIA empat bulan terakhir sebanyak 61 orang dari bulan Februari- Maret 2019.

CRM dapat digunakan sebagai jembatan pelayanan kesehatan kepada akseptor KB dalam hal penyampaian informasi terkait kontrasepsi, misalnya informasi kepada akseptor KB untuk mendapatkan pelayanan $\mathrm{KB}$ sesuai jadwal. meningkatkan kepatuhan akseptor dalam kunjungan ulang $\mathrm{KB}$ suntik dapat digunakan aplikasi CRM menggunakan teknologi Short Message Service (SMS), sehingga dengan penerapan aplikasi CRM menggunakan teknologi SMS maka informasi yang berkaitan dengan kontrasepsi dan jadwal kunjungan $\mathrm{KB}$ tersampaikan secara tepat sasaran, tepat waktu dan relevan. Sehingga akseptor diharapkan melakukan kunjungan ulang KB tepat waktu atau sesuai jadwal sehingga dapat menurunkan resiko kegagalan penggunaan sistem KB (Sutrisno Asmo Trismianto, 2019).

Menurut penelitian lain yang bejudul Hubungan Penggunaan Alat Kontrasepsi Hormonal Dengan Peningkatan Berat Badan Pada Akseptor KB menyatakan ada hubungan yang bermakna antara kontrasepsi hormonal dengan peningkatan berat badan. Frekuensi terbanyak adalah akseptor $\mathrm{KB}$ dengan penggunaan kontrasepsi hormonal $>6$ bulan sebanyak 34 orang $(68 \%)$ dan yang mengalami peningkatan berat badan dengan penggunaan kontrasepsi hormonal > 6 bulan juga merupakan frekuensi terbanyak sebanyak 28 orang (82\%) (Manurung, 2018).

Berdasarkan latar belakang masalah diatas, maka peneliti tertarik untuk meneliti "Pengaruh Penerapan Metode CRM (Costemer Relationship Management) Terhadap PUS (Pasangan Usia Subur) dan Aseptor KB khususunya jenis KB Hormonal Untuk Meningkatkan Kepatuhan Berkunjung Sesuai Jadwal Di Rumah Sakit Umum Imelda
Pekerja Indonesia (RSU IPI) Medan Tahun 2019”.

\section{METODE}

\section{Jenis dan Rancangan Penelitian}

Penelitian ini menggunakan kuantitatif yaitu metode penelitian yang berlandaskan pada filsafat positivisme, digunakan untuk meneliti pada populasi atau sampel tertentu, pengumpulan data menggunakan instrument penelitian, analisis data bersifat kuantitatif/statistik dengan tujuan untuk menguji hipotesis yang telah ditetapkan (Sugiyono, 2013). Jenis penelitian yang digunakan dalam penelitian ini Quasy eksperimen design tanpa pembanding. Dengan pendekatan One Group Pre Test-Post Test yang hanya mempergunakan kelompok eksperimen saja, tanpa kelompok control (pembanding).penelitian ini pengujian pertama (pre test) yang memungkinkan peneliti dapat menguji perubahan-perubahan yang terjadi setelah adanya eksperimen (program). Dengan kata lain dalampenelitian eksperimen ini mencoba meneliti metode CRM (Costemer RelationshipManagement) terhadap PUS (Pasangan Usia Subur) dan aseptor KB khususnya jenis KB hormonal untuk meningkatkan kepatuhan berkunjung kembali sesuai jadwaldi Rumah Sakit Imelda Pekerja Indonesia Medan.

$\mathrm{O}_{1}$ $\mathrm{O}_{2}$

O1: Pretest : sebelum diterapakn Metode CRM (Costemer Relationship Management) $\mathrm{O} 2$ : Posttest : sesudah diterapkanCRM (Costemer Relationship Management)

$\mathrm{X}$ : Intervensi : diterapkan CRM (Costemer Relationship Management) dengan metode SMS untuk meningkatkan kepatuhan Aseptor KB berkunjung kembali sesuai jadwal.

\section{Waktu Penelitian}

Penelitian ini dilakukan pada bulan Februari-April 2019, Waktu penelitian dihitung mulai dari pembuatan proposal sampai penyusunan laporan dan publikasi penelitian. Penelitian ini dilakukan di Rumah Sakit Imelda Pekerja Indonesia Medantepatnya di ruangan BKIA. 


\section{Populasi}

Populasi adalah wilayah generalisasi yang terdiri atas obyek atau subyek yang mempunyai kuantitas dan karakteristik tertentu yang di tetapkan oleh peneliti untuk dipelajari dan kemudian ditarik kesimpulannya (Sugiyono, 2011).Populasi dalam penelitian ini adalah PUS (Pasangan Usia Subur) yang berkunjung ke Ruang BKIA Rumah Sakit Imelda Pekerja Indonesia Medan.

\section{Sampel}

Sampel adalah sebagian besar dari jumlah dan karakteristik yang dimiliki oleh populasi (Notoatmodjo, 2012). Sampel dalam penelitian ini PUS (Pasangan Usia Subur) di ruang BKIA di RSU Imelda Pekerja Indonesia Medan. Dengan teknik pengambilan sampel adalah Non probability Sampling dengan metode Accidental sampling.

\section{Tehnik Pengumpulan Data}

Sebelum melakukan proses pengumpulan data, tahap awal yang harus dilakukan adalah melakukan persiapan untuk kelancaran pelaksanaan penelitian, berupa surat izin penelitian dan survey awal ke tempat yang akan dijadikan lokasi penelitian. Selain melakukan survey terlebih dahulu, peneliti juga harus melakukan pendekatan kepada para PUS di ruang BKIA Rumah Sakit Imelda Pekerja Indonesia Medan yang akan dijadikan responden pada penelitian yang akan dilakukan. Hal ini bertujuan menjelaskan alasan dan tujuan dari informed consent kepada responden. Peneliti harus menjelaskan kepada responden bahwa penelitian yang akan dilakukan ini tidak akan merugikan dan tidak akan berdampak negatif kepada mental maupun fisik dan kerahasiaan responden tetap terjaga. Setelah semua persyaratan diatas terpenuhi, kemudian dilaksanakan proses pengambilan data dari tempat penelitian.

\section{Data primer}

Data yang diperoleh sendiri oleh peneliti dengan melakukan pengukuran, pengamatan, survey, wawancara terhadap responden dengan menggunakan kuesioner yang disusun berdasarkan konsep tertulis dan lain-lain.Data sekunder

Data yang diperoleh dari pihak lain/ badan instansi yang secara rutin mengumpulkan data. Adapun data sekunder yang dipakai dalam penelitian ini adalah data yang telah diterbitkan oleh instansi-instansi terkait seperti, Badan Pusat Statistik, Dinas Pengendalian Penduduk Dan KB Kota Medan, BKKBN Sumatera Utara, laporan dan catatan atau dokumen pasien berKB di ruang BKIA Rumah Sakit Imelda Pekerja Indonesia Medan.

\section{Data tersier}

Data yang diperoleh dari hasil penelitian dan jumlah yang telah di publikasikan/ dikomplikasikan dari pihak lain dalam bentuk tabel. Pada penelitian ini data tersier diambil dari Jurnal Kesehatan Keluarga, Jurnal Kebidanan, penelitian sebelumnya mengenai CRM (Costemer Relationship Management) dan lain sebagainya.

\section{Variabel}

Variabel adalah karakteristik yang diamati yang mempunyai variasi nilai dan merupakan operasionalisasi dari suatu konsep agar dapat diteliti secra empiris atau ditentukan tingkatnya (Setiadi, 2007). Variabel bebas (independen) adalah variabel yang mempengaruhi atau menjadi sebab perubahannya atau timbulnya variabel dependen (Sugiyono, 2011), variabel independen pada penelitian ini adalah penerapan Model Shared Decision Making. Variabel terikat (dependen) merupakan variabel yang dipengaruhi atau yang menjadi akibat, karena adanya variabel bebas (Sugiyono, 2011), Variable dependen pada penelitian ini adalah sikap patuh atau tidak patuhnya Pasangan Usia Subur dan Aseptor KB untuk berkunjung kembali sesusai jadwal.

\section{Defenisi Operasional}

Operasional merupakan penjelasan semua variabel dan istilah yang akan digunakan dalam penelitian secara operasional sehingga akhirnya mempermudah pembaca dalam mengartikan makna.

Tabel 1. Defenisi Operasional

\begin{tabular}{|c|c|c|c|c|c|c|}
\hline No & $\begin{array}{c}\text { Variabel yang } \\
\text { diteliti }\end{array}$ & $\begin{array}{c}\text { Defenisi } \\
\text { operasional }\end{array}$ & Alat ukur & Kriteria & $\begin{array}{l}\text { Skala } \\
\text { ukur }\end{array}$ & Skor \\
\hline
\end{tabular}


Jurnal Ilmiah Keperawatan Imelda

http://jurnal.uimedan.ac.id/index.php/JURNALKEPERAWATAN e-ISSN : 2597-7172 p-ISSN : 2442-8108

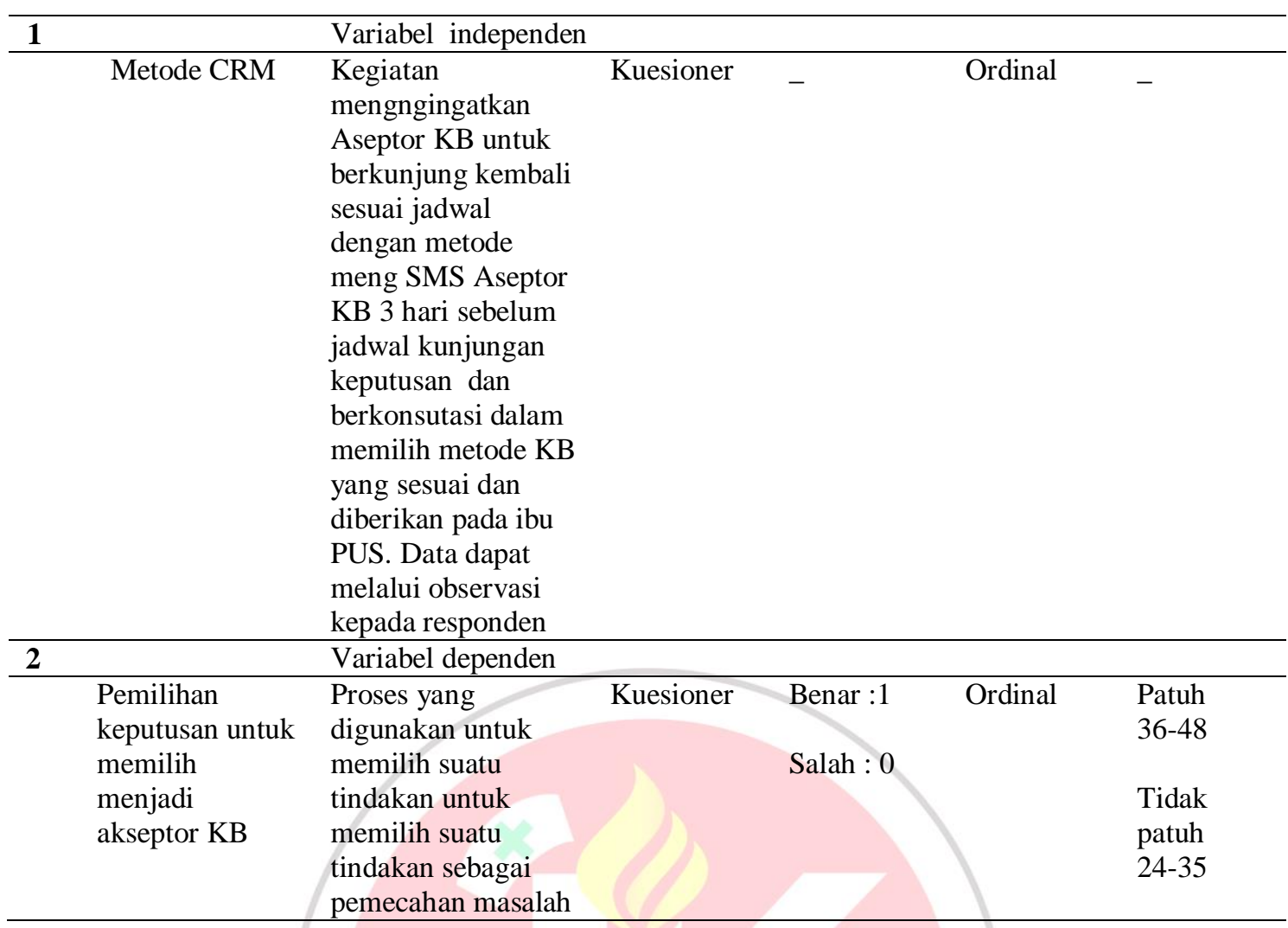

\section{Teknik analisa data}

\section{Analisa Univariat}

Analisa univariat digunakan untuk mendeskripsikan distribusi frekuensi dari masing-masing variabel penelitian. Analisa ini digunakan untuk memperoleh gambaran pada masing-masing variabel independen yang meliputi penerapan shared decision making model.

\section{Analisa Bivariat}

Analisis ini untuk mengetahui pengaruh Pengaruh Penerapan Metode CRM (Costemer Relationship Management) Terhadap PUS (Pasangan Usia Subur) dan Aseptor KB khusunya jenis KB Hormonal Untuk Meningkatkan Kepatuhan Berkunjung Sesuai Jadwaldi Rumah Sakit Imelda Pekerja Indonesia Medan tahun 2019. Dengan menggunakan uji paired t test.

\section{HASIL}

\section{Hasil Univariat}

Setelah dilakukannya penelitian dengan judul "Pengaruh Penerapan Metode CRM (Costemer Relationship Management) Terhadap PUS (Pasangan Usia Subur) dan Aseptor KB khususnya jenis KB Hormonal
Untuk Meningkatkan Kepatuhan Berkunjung Sesuai Jadwaldi Rumah Sakit Imelda Pekerja Indonesi (IPI) Medan tahun 2019" terhadap 30 responden yang diambil dengan cara purposive sampling maka diperoleh hasil sebagai berikut:

\section{Data Umum}

Tabel 2. Distribusi Karakteristik Responden Berdasarkan Umur Tentang Pengaruh Penerapan Metode CRM (Costemer

Relationship Management) di Rumah Sakit Imelda Pekerja Indonesia Medan Tahun 2019

\begin{tabular}{cccc}
\hline No & Karakteristik & F & \% \\
\hline 1 & $20-24$ & 8 & 26,7 \\
\hline 2 & $25-29$ & 12 & 40,0 \\
\hline 3 & $30-34$ & 4 & 13,3 \\
\hline 4 & $35-39$ & 6 & 20,0 \\
\hline & Jumlah & $\mathbf{3 0}$ & $\mathbf{1 0 0}$ \\
\hline
\end{tabular}

Berdasarkan table 2 diatas terlihat bahwa mayoritas responden yang interval usianya 25 29 tahun sebanyak 12 orang (40 \%), sedangkan minioritas responden yang interval usianya 30-34 tahun sebanyak 4 orang $(13,3$ $\%)$.

Tabel 3. Distribusi Karakteritik Responden Berdasarkan Pendidikan TentangPengaruh 
Penerapan Metode CRM (Costemer

Relationship Management)di Rumah Sakit Imelda Pekerja Indonesia Medan Tahun 2019

\begin{tabular}{cccc}
\hline No & Karakteristik & $\mathbf{F}$ & $\mathbf{\%}$ \\
\hline 1 & SD & 2 & 6,7 \\
\hline 2 & SMP & 4 & 13,3 \\
\hline 3 & SMA & 6 & 20,0 \\
\hline 4 & D3 & 7 & 23,3 \\
\hline 5 & SARJANA & 11 & 36,7 \\
\hline & & Jumlah & $\mathbf{3 0}$ \\
\hline
\end{tabular}

Berdasarkan tabel 3 diatas dapat dilihat bahwa bahwa mayoritas responden berdasarkan pendidikan Sarjana sebanyak 11 orang $(36,7 \%)$ sedangkan minoritas responden berdasarkan pendidikan SD sebanyak 2 $(6,7 \%)$.

Tabel 4. Distribusi karakteristik responden berdasarkan pekerjaan

tentangPengaruhPenerapan Metode CRM

(Costemer Relationship Management) di

Rumah Sakit Imelda Pekerja Indonesia Medan Tahun 2019

\begin{tabular}{cccc}
\hline No & Karakteristik & F & \% \\
\hline 1 & PNS & 10 & 33,3 \\
\hline 2 & IRT & 11 & 36,7 \\
\hline 3 & Pegawai swasta & 9 & 30,0 \\
\hline 4 & Wiraswasta & 0 & 0 \\
\hline & Jumlah & $\mathbf{3 0}$ & \\
\hline
\end{tabular}

Berdasarkan tabel 4 diatas dapat dilihat bahwa mayoritas responden berdasarkan pekerjaan ibu rumah tangga sebanyak 11 orang $(36,7 \%)$, sedangkan minoritas responden berdasarkan pekerjaan Wiraswasta sebanyak 0 orang $(0 \%)$.

Tabel 5. Distribusi Karakteristik Responden Berdasarkan Jumlah Anak Tentang Pengaruh Penerapan Metode CRM (Costemer Relationhip Management) di Rumah Sakit Imelda Pekerja Indonesia Medan Tahun 2019

\begin{tabular}{cccc}
\hline No & Karakteristik & F & \% \\
\hline 1 & $<2$ Orang & 26 & 86,7 \\
\hline 2 & $>2$ Orang & 4 & 13,3 \\
\hline & Jumlah & $\mathbf{3 0}$ & $\mathbf{1 0 0}$ \\
\hline
\end{tabular}

Berdasarkan tabel 5 diatas terlihat bahwa mayoritas responden yang memliki anak $<2$ Orang sebanyak 26 orang $(86,7 \%)$, sedangkan minioritas responden yang memliki anak $>2$ Orang sebanyak 4 orang (13,3\%).

Sebelum (pre) dan sesudah (post) diberi Pengaruh Penerapan Metode CRM (Costemer Relationship Management) di
Rumah Sakit Imelda Pekerja Indonesia Medan Tahun 2019

Tabel 6. Pre

\begin{tabular}{cccc}
\hline No & Karakteristik & F & \% \\
\hline 1 & Negative & 28 & 93,03 \\
\hline 2 & Positif & 2 & 100,0 \\
\hline & Jumlah & $\mathbf{3 0}$ & $\mathbf{1 0 0}$ \\
\hline
\end{tabular}

Tabel 7. Post

\begin{tabular}{cccc}
\hline No & Karakteristik & F & \% \\
\hline 1. & Positif & 30 & 100,0 \\
\hline & Jumlah & $\mathbf{3 0}$ & $\mathbf{1 0 0}$ \\
\hline
\end{tabular}

Sikap Pasangan Usia Subur (PUS) Sebelum (pre) dan sesudah (post) diterapkan Metode CRM (Costemer Relationship Management)di Rumah Sakit Imelda Pekerja Indonesia (IPI) Medan tahun 2019

Tabel 8. Sikap PUS Sebelum diterapkan

Metode CRM (Costemer Relationship Management)(pre-test)

\begin{tabular}{cccc}
\hline No & Karakteristik & F & \% \\
\hline 1 & Negative & 27 & 90,0 \\
\hline 2 & Positif & 3 & 10,0 \\
\hline & Jumlah & $\mathbf{3 0}$ & $\mathbf{1 0 0}$
\end{tabular}

Berdasarkan tabel 8 diatas terlihat bahwa sebelum penerapan Metode CRM (Costemer Relationship Management) responden yang bersikap Positif sebanyak 3 orang (10,0\%), sedangkan responden yan bersikap Negatif sebanyak 27 orang $(90,0 \%)$.

Tabel 9. Sikap PUS Sesudah diterapkan Metode CRM (Costemer Relationship Management) (post-test)

\begin{tabular}{cccc}
\hline No & Karakteristik & F & \% \\
\hline 1 & Positif & 30 & 100,0 \\
\hline & Jumlah & $\mathbf{3 0}$ & $\mathbf{1 0 0}$ \\
\hline
\end{tabular}

Berdasarkan tabel 9 diatas terlihat bahwa mayoritas responden yang bersikap negatif 0 $(0 \%)$ dan yang bersikap positf 30 orang $(100,0 \%)$ sudah diterapkan metode CRM.

\section{Hasil Bivariat}

Pada penelitian ini data yang diperoleh dapat dianalisa dengan analisis bivariate yaitu untuk mengetahui Pengaruh Penerapan Metode CRM (Costemer Relationship Management) Terhadap PUS (Pasangan Usia Subur) Khususnya Aseptor KB Untuk Meningkatkan Kepatuhan Berkunjung Sesuai Jadwal di Rumah Sakit Imelda Pekerja Indonesi (IPI) Medan tahun 2019. 
Perbedaan Sikap Pasangan usia subur terhadap pemilian keputusan Keluarga Berencana

Berdasarkan penelitian, penerapan Meto de CRM (Costemer Relationship
Management) terhadap sikap pasangan usia subur dalam pemilihan keputusan keluarga berencana dapat dilihat pada tabel hasil uji pairet $t$ trstdi bawah ini.

\begin{tabular}{|c|c|c|c|c|c|c|}
\hline & $\begin{array}{r}\text { Paired D } \\
95 \% \text { Confidenc } \\
\text { Diffe }\end{array}$ & erval of the & \multirow[b]{2}{*}{$\mathrm{t}$} & \multirow[b]{2}{*}{ df } & \multirow{2}{*}{$\begin{array}{l}\text { Sig. (2- } \\
\text { tailed) }\end{array}$} \\
\hline & & Lower & Upper & & & \\
\hline Pair 1 & pretest - posttest & $-12,51344$ & $-9,88656$ & $-17,440$ & &, 000 \\
\hline
\end{tabular}

Ket :

$\mathrm{P}<0,05$ maka ada pengaruh penerapan Metode CRM (Costemer Relationshi Management) sebelum dengan sesudah. Berdasarkan tabel diatas penerapan Metode CRM (Costemer Relationship Management) Terhadap PUS (Pasangan Usia Subur) dan Aseptor KB khususnya jenis KB Hormonal Untuk Meningkatkan Kepatuhan Berkunjung kembali Sesuai Jadwal sangat berpengaruh. Sebelum diterapkan Metode CRM (Costemer Relationship Management) di pilih PUS yang tidak mengetahui metode CRM untuk kepatuhan berkunjung kembali dengan SMS sebanyak 27 orang $(90,0 \%)$, sedangkan sesudah diterapkan Metode CRM (Costemer Relationship Management) sebanyak 30 orang $(100,0 \%)$.

\section{PEMBAHASAN}

Pemilihan Keputusan ber KB pada Pasangan Usia Subur

Hasil penelitian yang dilakukan peneliti didapatkan bahwa responden berubah persepsi tentangditerapkan Metode CRM (Costemer Relationship Management) untuk berkunjung ulang sesusi jadwal yang di tetapkan melalui sistem SMS berdasarkan distribusi umur, pendidikan, pekerjaan dan jumlah anak. Distribusi umur mayoritas responden yang interval usianya 25-29 tahun sebanyak 12 orang (40\%), sedangkan minioritas responden yang interval usianya 30-34 tahun sebanyak 4 orang (13,3\%), mayoritas responden berdasarkan pendidikan Sarjana sebanyak 11 orang $(36,7 \%)$ sedangkan minoritas responden berdasarkan pendidikan SD sebanyak 2 $(6,7 \%)$, mayoritas responden berdasarkan pekerjaan ibu rumah tangga sebanyak 11 orang $(36,7 \%)$, sedangkan minoritas responden berdasarkan pekerjaan Wiraswasta sebanyak 0 orang $(0 \%)$, mayoritas responden yang memliki anak $<2$ Orang sebanyak 26 orang $(86,7 \%)$, sedangkan minioritas responden yang memliki anak > 2 Orang sebanyak 4 orang $(13,3 \%)$ dan di pilih PUS yang tidak mengetahui metode CRM untuk kepatuhan berkunjung kembali dengan SMSsebanyak 27 orang $(90,0 \%)$,sedangkan sesudah diterapkan metode CRM (Costemer Relationship Management) sebanyak 30 orang (100\%). Berdasarkan jawaban kuesioner yang didapatkan data bahwa diterapkan Metode CRM (Costemer Relationship Management) di pilih PUS yang tidak mengetahui metode CRMuntuk kepatuhan berkunjung kembali sesuai jadwal primigravida sebelum di terapkan metode CRM. petugas kesehatan juga mempengaruhi karena tidak memberikan informasi yang jelas kepada Aseptor KB jika tidak berkunjung kembali sesusi jadwal (Endang, 2015).

Sebelum di terapkan metode CRM, informasi dan edukasi klien ditanya tentang alasan mengapa tidak berkunjung kembali sesusi jadwal yang telah di tetapkan, pernahkan Aeptor KB mendapatkan metode lain selain Metode CRM, dan setujukah jika metode CRM ini di terapkan di pelayan kesehatan dan rumah sakit dan diberi kuesioner untuk diisi yang akan diberi skor Ountuk jawaban salah dan skor 1 untuk jawaban benar.

\section{Pengaruh Penerapan Metode CRM (Costemer Relationship Management)}

Hasil uji statistik dengan menggunakan uji Pairet $t$ test didapatkan nilai $\mathrm{p}$ value sebesar $0,0000 \mathrm{P}<0,05$ yang artinya ada pemgaruh penerapan Metode CRM (Costemer Relationship Management) Terhadap PUS (Pasangan Usia Subur) dan Aseptor KB 
khususnya jenis KB Hormonal Untuk Meningkatkan Kepatuhan Berkunjung kembali Sesuai Jadwal.

Penelitian ini sejalan dengan penelitian Sutrisno Asmo Trismianto ,Ningsih Surati. Pengembangan Model Customer Relationship Management Menggunakan Teknologi Sms Guna Meningkatkan Kepatuhan Akseptor Kb. Media Elektrika, Vol. 7 No. 2, Desember 2014. Penelitian ini telah berhasil menghasilkan model Customer Relationship Management menggunakan teknologi SMS guna meningkatkan kepatuhan akseptor KB yang diimplementasikan di BPM Susiana Amini yang terletak di desa Pondok Sukoharjo dengan didaptka hasil $\mathrm{p}$ value $0,0000 \mathrm{P}<0,05$.

\section{KESIMPULAN}

Berdasarkan hasil penelitian dan pembahasan, penelitian ini menyimpulkan bahwa :

1. Sebagian besar klien dengan ketidaktahuan tentang CRM (costemer relationship management) sebelum (pre) diberikan CRM (costemer relationship management), memiliki tingkat pengetahuan yang buruk/rendah di Rumah Sakit Imelda Pekerja Indonesia (IPI) Medan dengan persentase mencapai sebanyak 27 orang $(90,0 \%)$.

2. Ada pengaruh yang signifikan antara pemberian metode CRM (costemer relationship management) terhadap pus (pasangan usia subur) dan aseptor $\mathrm{KB}$ khususnya jenis KB Hormonal untuk meningkatkan kepatuhan berkunjung sesuai jadwal di Rumah Sakit Imelda Pekerja Indonesia (IPI) Medan. Hasil dari uji wilcoxson menunjukkan besar nilai signifikansi (p) sebesar 0.000. nilai signifikasin yang besar nya dibawah 0,05 mengindikasikan adanya pengaruh yang signifikan antara variabel pemberian metode CRM (costemer relationship management) terhadap PUS (pasangan usia subur) dan aseptor $\mathrm{KB}$ khususnya jenis KB Hormonal untuk meningkatkan kepatuhan berkunjung sesuai jadwal di rumah sakit.

\section{DAFTAR PUSTAKA}

Anafi.2013. Hubungan Tingkat Pengetahuan Akseptor KB Tentang Kontrasepsi Suntik
DMPA Dengan Kepatuhan Jadwal Penyuntikan Ulang. KTI.Sukoharjo: Prodi DIII Kebidanan Poltekkes Bhakti Mulia

Arinta, F, 2018. Efektivitas Program Kampung KB Guna Mewujudkan Keluarga Kecil Mandiri (Studi Kasus: Tiga Orang Penerima Program Kampung KB di Lingkungan IX Kelurahan Harjosari II). Univsersitas Sumatera Utara

BKKBN (Badan Koordinasi Keluarga Berencana Nasional). 2008. Program Pelayanan Keluarga Berencana (KB). Jakarta.

Danardatu, Aloysius Heru. 2003. Pengenalan Customer Relationship Management $(C R M)$. IlmuKomputer.Com. Diakses tanggal 15 Maret 2011.

Dasuki, D, dkk. 2018. Unimet need KB pada pasangan usia subur. Yogyakarta

Hartanto, Hanafi. 2004. Keluarga Berencana dan Kontrasepsi, Jakarta: PT.Pustaka Sinar Harapan.

Manurung, N. (2018). Hubungan Penggunaan Alat Kontrasepsi Hormonal Dengan Peningkatan Berat Badan Pada Akseptor Kb. Jurnal Ilmiah Keperawatan IMELDA, 4(1), 370.

Notoatmodjo, S. 2012. Promosi Kesehatan, teori dan aplikasi. Cetakan Jakarta:Rineka Cipta.

Notoatmodjo, S. 2012. Promosi Kesehatan, teori dan aplikasi. Cetakan Jakarta:Rineka Cipta

Program KKBPK dalam SDKI 2017 Jurnal Keluar, Informasi Kependudukan. KB dan Pengembanga: Jakarta.

Setiadi, 2007, Konsep \& Penulis Riset Keperawatan. Yogyakarta : rohima press.

Yunianingsih, Trian. 2009. Sistem Informasi Pelayanan Kunjungan Pasien $K B$ di Rumah Bersalin Delima Merkah Cicalengka. KTI. Jurusan Manajemen Informatika Fakultas Teknik dan Ilmu Komputer Universitas Komputer Indonesia: Bandung. 